Article

\title{
Exploring the Effects of Safety Climate on Worker's Safety Behavior in Subway Operation
}

\author{
Yongliang Deng ${ }^{1,2}$, Haolun Guo ${ }^{1, *}$, Miaomiao Meng ${ }^{1}$, Ying Zhang ${ }^{1}$ and Shuangshuang Pei ${ }^{1}$ \\ 1 School of Mechanics and Civil Engineering, China University of Mining and Technology, \\ Xuzhou 221116, China; dylcumt@cumt.edu.cn (Y.D.); TS19030175P32ME@cumt.edu.cn (M.M.); \\ TS19030226P31@cumt.edu.cn (Y.Z.); Peiss0827@cumt.edu.cn (S.P.) \\ 2 Research Center for Digitalized Construction and Knowledge Engineering, China University of Mining and \\ Technology, Xuzhou 221116, China \\ * Correspondence: TS19030134P31@cumt.edu.cn
}

Received: 15 September 2020; Accepted: 30 September 2020; Published: 9 October 2020

check for updates

\begin{abstract}
The safety climate is becoming more and more important in the processes of subway operation safety management due to various accidents. The research objective of this study is to explore the effects of safety climate and personal factors on safety behavior in subway operation. First, a conceptual model is developed based on the literature review and expert experience. Then, data are collected from 352 workers in the Xuzhou subway operation company by questionnaire survey. Third, the structural equation model is employed to do model analysis based on SPSS and AMOS, and the final model is achieved through a serious of model tests and modification. At last, the quantitative effect of safety climate on worker's safety behavior in subway operation is obtained and analyzed. The results show that the descending order of total influence effect of safety climate on safety behavior is safety attitude (0.36), safety communication (0.265), safety policy (0.238), safety education and training (0.1), management commitment (0.099), and safety participation (0.073), respectively. The total influence effects of mediator variables (safety awareness and safety ability) are 0.242 and 0.194 , respectively. This study would be beneficial by offering recommendations in regard to worker's safety behavior to raise the safety level in subway operation.
\end{abstract}

Keywords: subway operation; safety climate; safety behavior; structural equation model; public transportation

\section{Introduction}

In the last few decades, the effects of safety climate on worker's safety behavior have attracted the interests of many researchers in various industries [1-3]. Because of the different perspectives of researchers, the results of these studies have differed. Some researchers indicated that there is an existing direct relationship between safety climate and safety behavior, while other researchers argued that the relations should be mediated by other variables [4]. Due to the diverse behavior characteristics and influence factors in different industries, their quantitative relations must be somewhat different.

As the lifeblood of urban development, public transportation is related to urban development and residents' lives. Compared with other modes of transportation, public transportation plays a positive role in improving efficiency, saving resources, and reducing pollution. Cartenì et al. [5] mentioned that the e-Mobility Bus, as an environmentally friendly and powerful energy-saving system, plays an important role in sustainable urban transportation. Ko and Oh [6] pointed out that wireless charging trams overcome the shortcomings of traditional trams. Wireless charging electric trams can be powered remotely from wireless charging infrastructure on the railway and can store the remaining electricity in the battery. Macioszek et al. [7] indicated that the bicycle sharing system is an effective tool to 
promote various modes of transportation and can be used as an element to improve the sustainable transportation of cities. It brings great advantages in effectively reducing traffic congestion and using urban space. In many cities around the world, people tend to establish Park and Ride Systems in the suburbs, which enable users to combine personal transportation with public transportation, thereby helping to reduce the number of cars entering the city center [8]. Corazza et al. [9] believe that in urban transportation, local railways can not only solve the pollution problem of the urban environment, but also provide a larger capacity of transportation methods to solve the city's growing transportation demand. After the opening of the subway, due to its advantage of speed and rapidity compared with other means of transportation, it has attracted many passengers to transfer from other means of transportation to the subway.

The subway is an important part of urban public transport system in large cities. According to the statistical data provided by China's Ministry of Construction, up to 1 June 2020, 41 cities in total have been approved to construct subway systems by China's central government. Of those cities, 27 subway systems have been put into operation with a total length of approximately $4000 \mathrm{~km}$. In addition, there are still several other cities who have submitted their application to the central government. Owing to the nature of business and social significance of the subway system, its operation safety involves many issues, such as staff safety, passengers' safety, and the quality of the train service. Notwithstanding continuous improvements in subway operation that have been made with time, injuries and accidents occur in daily operation from time to time [10]. Safety and the steady operation of the subway system heavily relies on committed staff of the operations division working around the clock performing numerous running and maintenance activities. Unfortunately, Heinrich [11] indicated that approximate $88 \%$ of the preventable accidents were triggered by unsafe behavior. In reality, human error and unsafe behavior are critical causes of various accidents [12]. Similarly, human behavior exerts a tremendous impact on the reliability and safety of subway operation. For instance, owing to the errors of personnel operation, which were non-compliance with safety procedures, two trains collided on 27 September 2011, in Shanghai, resulting in 284 citizens injured and severe social influence. On 17 September 2019, eight passengers were injured when a train suddenly derailed tens of meters in front of the station while approaching Hung Hom station.

Unsafe behaviors of worker and passenger are one of the key predisposing factors of subway accidents. In China, most of the subway systems have been suffering from high intensity of operation due to the large volume of passengers [13]. Under such context, unsafe behaviors from staff and passenger can hardly be prevented or even held back, giving rise to personal, financial, and social costs at irregular intervals. From a recent study of Wan et al. [14], 65\% of the subway operation incidents from 2002 to 2012 were caused by unsafe passenger behaviors. Within that category, suicide is the most typical unsafe behavior and has been given much attention $[15,16]$. There are also variety kinds of unsafe behaviors regarding staff, such as exceeding speed limit, violation scheduling, management deficiency, and poor maintenance, to name a few. For example, the accident that occurred in Beijing subway on 5 July 2011, was triggered by the unsafe behavior of maintenance staff, and a similar accident occurred at Line 10, Shenzhen Subway, on 27 August 2019. Zhang et al. [17] grouped precursors to subway accidents into three categories, including human factors, equipment factors, and environmental factors. The statistical analysis of three factors came to the conclusion that unsafe behavior is an important direct cause of operation accidents.

For the purpose of preventing subway accidents, one of the key issues is to acknowledge how to eliminate unsafe behavior and promote safe behavior. Kyriakidis et al. [18] indicated that a better safety climate with commitment and involvement is appropriate to reduce subway accidents caused by human failure based on precursor analysis. Yuting chen et al. [19] indicated that safety climate not only affected workers' safety performance but also indirectly affected their psychological stress. To our knowledge, there is no systematic study which has explored the effect of safety climate on worker's safety behavior in subway operation. The mechanisms of safety climate's influence on worker's safety behavior is little known in subway operation. Additionally, its specific dimensions 
also need further exploration. Hence, from the perspective of improving subway operation safety, identifying and quantifying the effect of the safety climate on safety behavior is of great significance due to practical necessity. Furthermore, targeted measures and regulations can be established to promote safety behavior during daily work. Within such a background, an empirical study is implemented to establish and validate a conceptual model of the effects of safety climate on worker' safety behavior in subway operation.

The rest of this paper is organized as follows. In Section 2, a literature review is presented on safety climate and safety behavior, which contributes to the production of the theoretical basis for developing the conceptual model. The structural equation model and data collection are expatiated in Section 3. Subsequently, the results are displayed and a discussion of findings, potential contributions, limitations, and suggestions is provided. In the end, the conclusions of this study are summarized and analyzed.

\section{Literature Review}

\subsection{Safety Climate}

Zohar [20] originally developed the concept of safety climate, and constructed a 40-item measure of organizational safety climate. Indicated by Zohar, safety climate could be utilized as a powerful tool for understanding safety behavior. The definition of safety climate was introduced by Neal and Griffin as "individual perceptions of policies, procedures, and practices relating to safety in the workplace". Petitta believes that safety climate is defined as a manifestation of these beliefs, principles and policies in workplace practices and behaviors. Following this definition, safety climate could be deemed as a current reflection of underlying safety culture [21-23]. Various studies were carried out to investigate the influencing factors of safety climate, along with establishing numerous assessment instruments. Nevertheless, in different industries, the influencing factors of safety climate are not in agreement, and sometimes they would be contradictory [24,25]. In spite of inconsistencies, it had been empirically proven that safety climate could have a significant impact on safety-related behaviors across various industries [26-31]. The general conclusion would be that workers representing workplaces with a more positive safety climate demonstrate higher levels of hazard recognition and safety risk perception, and the better the safety climate, the less the unsafe behaviors and related accidents. For instance, empirical evidence supported this conclusion in construction industry [32,33]. Li et al. [34] result show that six SCDs (workers' self-perception of safety, workers' involvement in safety, co-workers' interaction, safety environment, safety management involvement, and safety personnel support) were significantly important to the safety climate of the construction teams.

The importance of safety climate has been widely accepted. For measuring safety climate, a number of key factors encompassing safety commitment, safety policy, safety training, and social support were employed in various studies. Among those factors, safety commitment for management should be the most fundamental one. Only when perceiving high commitments on safety made by senior managers would the supervisors and workers show their increasing willingness to enhance the safety level to cater to the safety management expectations. The majority of existing safety climate measures place either direct or indirect emphasis on leader safety commitment [35]. The influence of management safety commitment on safety outcomes was explored and uncovered in some research [36,37]. Safety policy can be seen as the surface manifestation of belief and value concerning operation safety in company. It is primarily about compliance with safety training, safety procedure, safety resource, and safety feedback. DeJoy et al. [38] indicated that safety policy plays an important role in safety climate. Safety training refers to vocational education and training in order to improve personal safety knowledge and skills. It is one of the important parts of safety climate while analyzing the relationship between safety performance and safety climate [39]. Social support, referring to safety support from coworkers and supervisors, was believed to be a crucial factor at the microscopic group level. The importance of social support consisted in the fact that the interactions among colleagues had an outstanding contribution 
to work behavior [29]. Social support has been demonstrated to encourage safety communication and safety performance to some extent $[40,41]$. Pressure from production could lead to a lower priority on safety determined by managers and staff, under which some basic safety activities might be ignored. Furthermore, production pressure could result in unsafe behaviors for the sake of fulfilling the required works and avoiding possible adverse consequences [36]. Han et al. [42] pointed out that perceived production pressure could bring about a degradation of safety management and an increase in accident rate. In addition, safety knowledge and safety motivation were also key factors. Campbell et al. [43] indicated that there are three determinants in work performance, including declarative knowledge, procedural knowledge, and motivation. Subsequently, declarative knowledge and procedural knowledge are gradually combined as safety knowledge in order to explain safety behavior. Christian et al. [44] indicated that safety motivation and safety knowledge were strongly related to safety performance.

From the above analysis, safety climate involves a wide range of factors, and the study of safety climate in different industries also occupy an increasingly important significance. The safety climate not only affects the safety performance of the enterprise, but also is closely related to the working environment and safety condition of the enterprise. The security climate has proven to have a positive and pervasive impact on a range of security outcomes at the individual and overall level [45].

\subsection{Safety Behavior}

Safety behavior refers to all behaviors in which people obey the work rules and can protect themselves, tools, equipment, and other materials in the event of a safety accident. Research about safety behavior has mainly paid attention to specific behaviors or actions exhibited by employees. From the perspective of organizations, safety behavior is regarded as compliance actions with safety policies and procedures, for instance, using protective facilities correctly and reducing exposures to potential hazards. Habitual noncompliance behaviors against safety procedures and policies may make the whole operating system vulnerable to failure, and it can be regarded as a root cause of incidents or accidents. Some subsequent studies related to safety behaviors supported this point of view. Hofmann and Stetzer [46] found that both the individual and group-level variables are associated with unsafe behaviors, and safety climate and unsafe behaviors were associated with actual accidents in American chemical processing plants, which suggested that exploring the mechanism of unsafe behavior was most essential to reducing noncompliance and enforce safety management. Griffin and Neal [47] classified safety-related behaviors into two kinds, namely safety compliant behaviors and safety participation behaviors. The first behavior was used to describe "the core safety activities that need to be carried out by individuals to maintain workplace safety", while the second one was deemed as "may not directly contribute to workplace safety, but do help to develop an environment that supports safety". Safety compliance describes adherence to core safety activities that must be carried out by individuals to maintain a safe workplace. Safety participation, with its voluntary nature, usually refers to safety behavior that extend normal requirements [48]. Based on the organization's rules and regulations, if an employee lacks safety participation, then the organization cannot punish the employee. If an employee takes safety actions, then no distinct rules and regulations are implemented for rewarding such behavior. That is, safety participation cannot be directly recognized through formal procedures [49].

A study by Neal and Griffin [50] supported the fact that staff would like to allocate effort to some discretional safety activities when perceiving safe working climate. A series of safety policies, rules, procedures, standards, regulations, and specific criteria within an organization or system were crucial to gain better safety outcomes, and safety initiative also played an important role at individual level [51]. Baysari et al. [52] concluded that violations occur regularly in the rail industry, and the majority of unsafe behaviors are caused by a slip in attention associated with decreased alertness and physical fatigue. Langford et al. [53] provided a novel model to analyze safety behavior in bicycle riding based on GPS data, and four types of unsafe behavior were evaluated, including wrong way 
riding, speed, compliance with traffic signals, and compliance with stop signs. It is supposed that this method could be extended to any kind of road user or vehicle. Aryee et al. [54] pointed out that safety initiative will lead to actions that minimize the occurrence of safety-related events and injuries. For example, promotion focus will motivate safety initiatives such as putting pressure on management to take steps to improve safety conditions, which will minimize the frequency of safety related events or near misses.

The importance of safety behavior has been recognized in the daily safety management. To improve the level of safety production, we must improve the unsafe behavior of employees. Human beings are the most active factor in safety production. The human factor is the main reason for the occurrence and prevention of safety accidents. Choi et al. [55] concluded that improving employees' willingness to comply with management norms is an effective way to improve employees' safety behavior. According to the conclusion of the comprehensive model, Guo et al. [36] suggest combining the strategies of "safety organization", "safety group", and "safety worker" to reduce the unsafe behavior on the construction site.

\subsection{Conceptual Model}

Based on existing research and the actual situation of subway operations, a conceptual model was established as shown in Figure 1. It contains a series of hypotheses, which can be introduced as follows.

Hypothesis 1a: Management commitment (MC) has a direct positive impact on safety awareness (SAW).

Hypothesis 1b: Management commitment (MC) has a direct positive impact on safety behavior (SB).

Hypothesis 2a: Safety communication (SC) has a direct positive influence on safety awareness (SAW).

Hypothesis 2b: Safety communication (SC) has a direct and positive influence on safety behavior (SB).

Hypothesis 3a: Safety policy (SPO) has a direct and positive influence on safety awareness (SAW).

Hypothesis 3b: Safety policy (SPO) has a direct and positive influence on safety behavior (SB).

Hypothesis 4a: Safety education and training (SET) have a direct positive influence on safety awarenes S (SAW).

Hypothesis 4b: Safety education and training (SET) have a direct positive impact on safety behavior (SB).

Hypothesis 4c: Safety education and training (SET) have a direct positive influence on safety ability (SAB).

Hypothesis 5a: Safety participation (SPA) has a direct and positive influence on safety awareness (SAW).

Hypothesis 5b: Safety participation (SPA) has a direct and positive influence on safety ability (SAB).

Hypothesis 6a: Safety attitude (SAT) has a direct and positive influence on safety awareness (SAW).

Hypothesis 6b: Safety attitude (SAT) has a direct and positive influence on safety behavior (SB).

Hypothesis 6c: Safety attitude (SAT) has a direct positive influence on safety ability (SAB).

Hypothesis 7a: Safety awareness ( $S A W$ ) has a direct positive influence on safety ability (SAB).

Hypothesis 7b: Safety awareness (SAW) has a direct positive influence on safety behavior (SB).

Hypothesis 8: Safety ability (SAB) has a direct and positive influence on safety behavior (SB). 


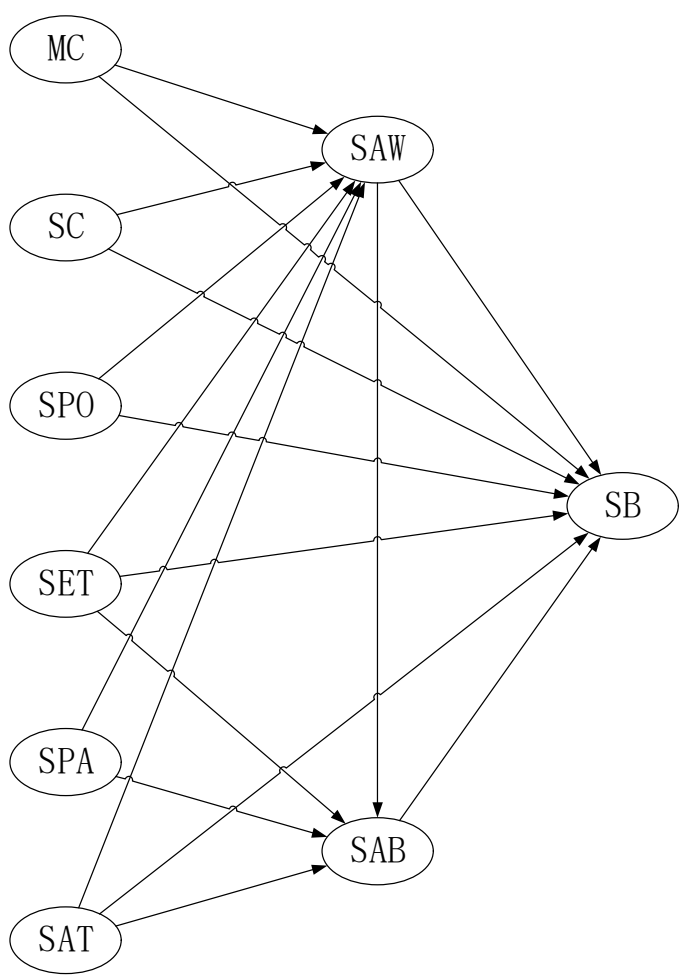

Figure 1. The conceptual model.

In addition, the item measures of model constructs are displayed in Table 1. The substance and content of the majority of the 39 questions has been adopted from the existing questionnaires of Al-Refaie [56], Guo et al. [36], Neal et al. [12], Vinodkumar and Bhasi [57], Vredenburgh [58], Zohar [20], and a variety of related reports. The items in this draft questionnaire had been discussed with safety experts and senior managers to ensure their validity. Then, a pilot study was performed in order to gain feedback and clarify these items.

Table 1. Safety climate, intermediate variable and safety behavior scale.

\begin{tabular}{|c|c|c|}
\hline Dimensions & Serial Number & Item \\
\hline \multirow{4}{*}{$\begin{array}{l}\text { Management Commitment } \\
(\mathrm{MC})\end{array}$} & $\mathrm{MC1}$ & Leaders attach importance to safety rules and regulations \\
\hline & MC2 & $\begin{array}{l}\text { Leaders are willing to put money into providing safety equipment or } \\
\text { safety insurance }\end{array}$ \\
\hline & MC3 & Leaders often make safety speeches or hold safety meetings \\
\hline & MC4 & $\begin{array}{l}\text { The leaders take active measures to correct the problems caused by } \\
\text { unsafe conditions }\end{array}$ \\
\hline \multirow{3}{*}{$\begin{array}{l}\text { Safety Communication } \\
\qquad(\mathrm{SC})\end{array}$} & $\begin{array}{l}\text { SC1 } \\
\text { SC2 }\end{array}$ & $\begin{array}{l}\text { Safety issues are often discussed among colleagues } \\
\text { You often discuss work safety issues with your direct supervisor }\end{array}$ \\
\hline & $\mathrm{SC} 3$ & $\begin{array}{l}\text { You have reported or reported to your supervisor on site safety concerns } \\
\text { and problems }\end{array}$ \\
\hline & $\mathrm{SC} 4$ & You are often notified of safety-related information in a timely manner \\
\hline \multirow{5}{*}{$\begin{array}{l}\text { Safety Policy } \\
\quad \text { (SPO) }\end{array}$} & SC5a & $\begin{array}{l}\text { The unit can make the quick response to the safety related question, the } \\
\text { safety inspection will result in feedback to you }\end{array}$ \\
\hline & SPO1 & The unit has formulated the quite perfect safety system standard \\
\hline & $\mathrm{SPO} 2$ & $\begin{array}{l}\text { The revised safety operating rules of the unit will not be too old and } \\
\text { cumbersome, not in line with the actual work }\end{array}$ \\
\hline & SPO3 & $\begin{array}{c}\text { The unit has earnestly implemented the safety reward and } \\
\text { punishment measures }\end{array}$ \\
\hline & $\mathrm{SPO} 4$ & $\begin{array}{c}\text { You can see a file or identification of the safe job specification at } \\
\text { your workplace }\end{array}$ \\
\hline
\end{tabular}


Table 1. Cont.

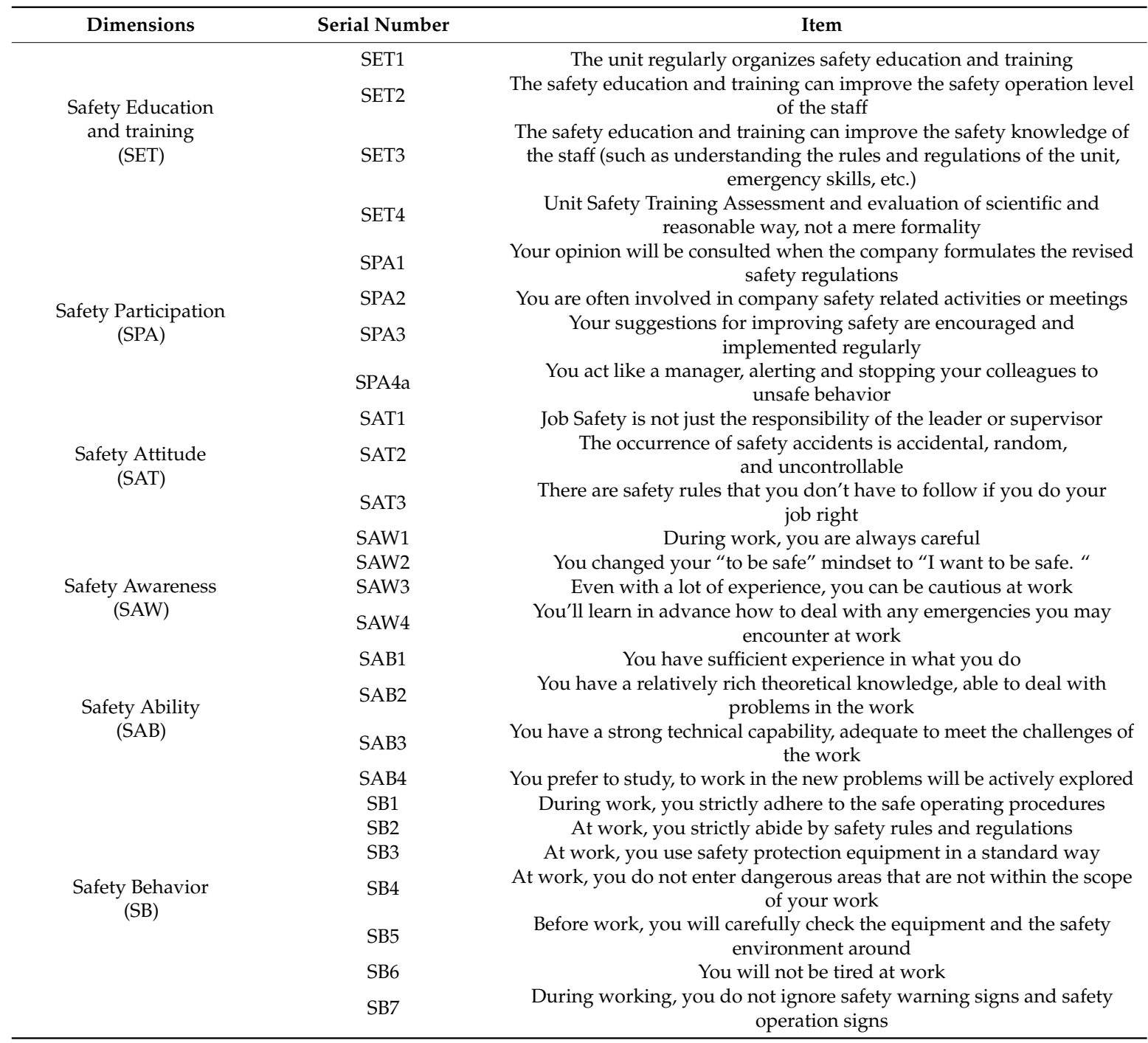

\section{Methodology}

\subsection{Structural Equation Model}

Structural equation model (SEM) is a powerful method to analyze and evaluate the causal relations based on statistic data and reasonable hypotheses [59-62]. There are two key points in SEM, one is using a series of regression equations to represent the causal processes, the other is modelling the structural relations pictorially to conceptualize the theory [56]. Relation hypothesis is the indispensable basis and guarantee for establishing a structural equation model. The hypothesized model could be tested in systematical analysis to judge to what extent it is matched with the statistical data.

The general procedures of applying SEM are as follows. First, according to existing knowledge and theories, a structural model of the relationships among identified variables is established based on hypothesis. Secondly, an investigation is implemented to gain the data of observed variables. Third, SEM is employed to verify the reliability and validity of the proposed model. Fourth, the final model is achieved by modifying the proposed model based on path analysis. At last, the results are obtained by calculating the final model. 


\subsection{Data Collection}

Questionnaire survey is one of the most popular approaches to collecting specific data, which is particularly applicable for cases in which direct data could not be obtained. In this research, the data collection was implemented in the manner of a two-stage process to keep its effectiveness.

Taking into account the good cooperation between the Xuzhou Metro Corporation and the China University of Mining and Technology, the subjects of this questionnaire are mainly subway operators of the Xuzhou Metro, that is, those who are or have been engaged in relevant subway operations and other staff with operational safety management. In order to make the scope of the study wider and draw more general conclusions, the questionnaire does not provide options for positions to ensure data are collected for senior and middle managers and workers at the grass-roots level. This research questionnaire is divided into three parts: the first part is the introduction, so that the survey subjects understand the significance and content of the survey; the second part is to understand the basic situation of the survey subjects, including the gender, age, length of service, and education; the third part is the main part of the questionnaire, which includes the safety climate scale, the intermediary variable scale, and the safety behavior scale.

This questionnaire uses the Likert 5-point scoring method, divided into the forward question and the reverse question; among the positive questions, "strongly agree", "agree", "general", "disagree", and "strongly disagree" correspond to $1,2,3,4$, and 5 points respectively. In contrast, in this questionnaire, the second and third questions about safety attitude are reverse questions.

In this study, 450 samples were distributed and 422 samples were collected. The recovery rate of the questionnaire was $93.8 \%$. After removing the invalid questionnaires, such as incomplete answers and identical answers, there were valid questionnaires 352 , and the effective rate was $83.4 \%$.

\section{Results}

\subsection{Demographic Characteristics}

In Table 2, the demographic characteristics of attendees are presented. As can be seen from Table 2, the age distribution of the respondents is mainly 21-30 years old and 31-40 years old in terms of age, while about half of them have worked for more than five years; the distribution of junior college, bachelor's degree and master's degree is more average. From the demographic characteristics of the sample, it can be seen that its variables are more in line with the actual situation, meet the sample requirements for this survey, and avoid the accidental factors caused by a single sample, which gives this study more universal and practical significance.

Table 2. Demographic characteristics of attendees.

\begin{tabular}{cccc}
\hline Variables & Type & Frequency & Percentage \\
\hline \multirow{2}{*}{ Gender } & Male & 301 & $85.5 \%$ \\
& Female & 51 & $14.5 \%$ \\
\multirow{2}{*}{ Age } & $21 \sim 30$ & 168 & $47.7 \%$ \\
& $31 \sim 40$ & 129 & $36.6 \%$ \\
& $41 \sim 50$ & 41 & $11.7 \%$ \\
Working years & $51 \sim$ & 14 & $4.0 \%$ \\
& $1 \sim 3$ & 100 & $28.4 \%$ \\
& $3 \sim 5$ & 60 & $17.0 \%$ \\
\multirow{2}{*}{ Education } & $5 \sim 7$ & 35 & $10.0 \%$ \\
& $7 \sim$ & 157 & $44.6 \%$ \\
& College and below & 109 & $31.0 \%$ \\
& University & 166 & $47.2 \%$ \\
& Master and above & 77 & $21.8 \%$ \\
\hline \multirow{3}{*}{} & & &
\end{tabular}




\subsection{Reliability Test}

There are four methods to measure reliability: test-retest coefficient, parallel-forms Coefficient, spit-half reliability and Cronbach's a. Cronbach's alpha $(\alpha)$ coefficient is powerful for testing the data reliability [63]. Cronbach's alpha $(\alpha)$ coefficient is currently the most commonly used method of reliability analysis, which can handle multiple scoring measurements and overcome the shortcomings of the partial split-half method and can be used in conjunction with exploratory factor analysis. Therefore, the Cronbach's alpha $(\alpha)$ coefficient is used in this paper.

In general, when the coefficient is greater than 0.7 , it means that the new scale is better, and there is no need to adjust the measuring tools; when the coefficient is higher than 0.8 , or even higher than 0.9 , it is in a very ideal state. We used statistical analysis software SPSS to further analyze the data. The values of Cronbach's $\alpha$ were calculated by SPSS 24.0, and the CITC (Corrected Item Total Correlation) and reliability analyses of the safety climate, mediator variables, and safety behavior are shown in Table 3.

Table 3. CITC and reliability analysis.

\begin{tabular}{|c|c|c|c|c|c|}
\hline Latent Variable & Items & CITC & Monomial $\alpha$ & $\alpha$ & Overall Cronbach's $\alpha$ \\
\hline \multirow{4}{*}{ Management Commitment (MC) } & MC1 & 0.778 & 0.855 & \multirow{4}{*}{0.892} & \multirow{39}{*}{0.942} \\
\hline & MC2 & 0.789 & 0.850 & & \\
\hline & MC3 & 0.760 & 0.861 & & \\
\hline & MC4 & 0.721 & 0.876 & & \\
\hline \multirow{5}{*}{ Safety Communication (SC) } & SC1 & 0.634 & 0.864 & \multirow{5}{*}{0.875} & \\
\hline & SC2 & 0.729 & 0.842 & & \\
\hline & SC3 & 0.724 & 0.843 & & \\
\hline & SC4 & 0.729 & 0.842 & & \\
\hline & SC5 & 0.702 & 0.848 & & \\
\hline \multirow{4}{*}{ Safety Policy } & SPO1 & 0.706 & 0.786 & \multirow{8}{*}{0.854} & \\
\hline & $\mathrm{SPO} 2$ & 0.658 & 0.805 & & \\
\hline & SPO3 & 0.655 & 0.814 & & \\
\hline & SPO4 & 0.696 & 0.789 & & \\
\hline \multirow{4}{*}{ Safety Education and Training } & SET1 & 0.680 & 0.824 & & \\
\hline & SET2 & 0.772 & 0.788 & & \\
\hline & SET3 & 0.794 & 0.776 & & \\
\hline & SET4 & 0.614 & 0.879 & & \\
\hline \multirow{4}{*}{ Safety Participation } & SPA1 & 0.749 & 0.819 & \multirow{4}{*}{0.867} & \\
\hline & SPA2 & 0.781 & 0.805 & & \\
\hline & SPA3 & 0.834 & 0.782 & & \\
\hline & SPA4 & 0.526 & 0.899 & & \\
\hline \multirow{3}{*}{ Safety Attitude } & SAT1 & 0.597 & 0.704 & \multirow{3}{*}{0.772} & \\
\hline & SAT2 & 0.545 & 0.759 & & \\
\hline & SAT3 & 0.683 & 0.609 & & \\
\hline \multirow{4}{*}{ Safety Awareness } & SA1 & 0.663 & 0.787 & \multirow{4}{*}{0.831} & \\
\hline & SA2 & 0.667 & 0.787 & & \\
\hline & SA3 & 0.698 & 0.770 & & \\
\hline & SA4 & 0.621 & 0.804 & & \\
\hline \multirow{4}{*}{ Safety Ability } & SAB1 & 0.668 & 0.784 & \multirow{4}{*}{0.831} & \\
\hline & SAB2 & 0.705 & 0.766 & & \\
\hline & SAB3 & 0.705 & 0.765 & & \\
\hline & SAB4 & 0.564 & 0.829 & & \\
\hline \multirow{7}{*}{ Safety Behavior } & SB1 & 0.669 & 0.883 & \multirow{7}{*}{0.895} & \\
\hline & SB2 & 0.655 & 0.886 & & \\
\hline & SB3 & 0.742 & 0.875 & & \\
\hline & SB4 & 0.732 & 0.876 & & \\
\hline & SB5 & 0.719 & 0.877 & & \\
\hline & SB6 & 0.703 & 0.880 & & \\
\hline & SB7 & 0.664 & 0.884 & & \\
\hline
\end{tabular}


It can be seen from the above table that the CITC values of each initial scale are all greater than 0.5 and each value is greater than 0.7 , which satisfies the related critical value condition and indicates that each initial total scale and subscale has good consistency and stability.

\subsection{Exploratory Factor Analysis}

Exploratory factor analysis (EFA) is one of the most commonly used methods to test the validity of structure. It is a technique to explore the basic structure of multivariable and deal with multivariate dimensionality reduction, which is used to identify potential factors in potential structures. In this study, in order to avoid using the original data repeatedly, 150 samples were randomly selected, and EFA was implemented with SPSS 24.0 software. The Kaiser-Meyer-Olkin (KMO) and Bartlett's sphericity tests were used to determine the correlation between the potential conformations. It is generally believed that exploratory factor analysis is appropriate when KMO is greater than 0.6 and the significance probability of Bartlett sphere test is less than $0.001 \mathrm{Sig}$. In exploratory factor analysis, if the item factor load of the latent variable is greater than 0.5 , the scale has good convergence validity. The item factor load of the latent variable was less than 0.5 in the other variables, which indicated that the latent variable had good discriminant validity. Exploratory factor analysis was used to verify the validity of the scale.

Firstly, the exploratory factors of safety climate were analyzed. SPSS 24.0 was used for exploratory factor analysis of the safety climate scale. KMO and Bartlett's tests of sphericity were performed on the 24 items of the safety climate. As shown in Table 4, KMO is suitable for factor analysis. The probability of significance of the $\chi^{2}$ statistic is close to 0 , less than $1 \%$, indicating the data is relevant and meets the criteria.

Table 4. Safety climate's KMO and Bartlett test.

\begin{tabular}{ccc}
\hline \multicolumn{2}{c}{ KMO } & $\mathbf{0 . 8 9 6}$ \\
\hline \multirow{3}{*}{ Bartlett's test of sphericity } & Approximate chi-square & 2728.548 \\
& df & 276 \\
& Significance probability & 0.000 \\
\hline
\end{tabular}

The factor extraction method was principal component analysis, and the rotation method was the maximum variance method. All factors with characteristic value greater than 1 were extracted. Six factors were obtained by orthogonal rotation. The characteristic roots were 11.029, 2.191, 1.549, $1374,1.115$, and 1.004, respectively, and the cumulative variance interpretation rate was $76.092 \%$. By analyzing the items of measurement of different factors, it is proved that it is reasonable to divide the dimension of safety into management commitment, safety communication, safety policy, safety education and training, safety participation, and safety attitude.

Table 5 is the rotating composition matrix of the six factors. First, the items with factor loading less than 0.5 were checked and deleted under the principal component, so SC5 and SPA4 were deleted. After eliminating the items with small factor loads and those that do not conform to the preset dimensions, a total of 22 items remained. 
Table 5. Rotating composition matrix of safety climate.

\begin{tabular}{ccccccc}
\hline & \multicolumn{5}{c}{ Compositions } \\
\cline { 2 - 7 } Items & $\mathbf{1}$ & $\mathbf{2}$ & $\mathbf{3}$ & $\mathbf{4}$ & $\mathbf{5}$ & $\mathbf{6}$ \\
\hline SPO4 & 0.750 & 0.174 & 0.038 & 0.229 & 0.292 & 0.275 \\
SPO1 & 0.749 & 0.255 & 0.126 & 0.156 & 0.090 & 0.201 \\
SPO2 & 0.739 & 0.117 & 0.125 & 0.099 & 0.006 & 0.158 \\
SPO3 & 0.707 & 0.230 & 0.283 & 0.056 & 0.211 & 0.116 \\
SC5 & 0.661 & 0.251 & 0.155 & 0.304 & 0.392 & 0.091 \\
MC2 & 0.188 & 0.819 & 0.242 & 0.189 & 0.145 & 0.113 \\
MC3 & 0.148 & 0.816 & 0.118 & 0.242 & 0.250 & 0.066 \\
MC1 & 0.275 & 0.806 & 0.011 & 0.148 & 0.135 & 0.161 \\
MC4 & 0.268 & 0.710 & 0.281 & 0.108 & 0.117 & 0.184 \\
SPA1 & 0.190 & 0.170 & 0.848 & 0.224 & 0.081 & 0.025 \\
SPA2 & 0.133 & 0.153 & 0.835 & 0.213 & 0.223 & 0.029 \\
SPA3 & 0.202 & 0.180 & 0.798 & 0.176 & 0.315 & 0.049 \\
SET2 & 0.134 & 0.143 & 0.225 & 0.807 & 0.266 & 0.199 \\
SET3 & 0.119 & 0.205 & 0.219 & 0.806 & 0.285 & 0.163 \\
SET1 & 0.250 & 0.317 & 0.172 & 0.727 & 0.135 & 0.091 \\
SET4 & 0.343 & 0.128 & 0.421 & 0.553 & 0.150 & 0.104 \\
SC3 & 0.208 & 0.169 & 0.129 & 0.253 & 0.754 & 0.080 \\
SC2 & 0.279 & 0.239 & 0.393 & 0.222 & 0.617 & -0.019 \\
SC1 & 0.331 & 0.309 & 0.193 & 0.272 & 0.601 & 0.143 \\
SPA4 & -0.024 & 0.072 & 0.424 & 0.195 & 0.600 & 0.322 \\
SC4 & 0.505 & 0.346 & 0.208 & 0.142 & 0.529 & 0.139 \\
SAT3 & 0.163 & 0.204 & -0.053 & 0.080 & 0.202 & 0.833 \\
SAT2 & 0.313 & 0.118 & -0.032 & 0.098 & 0.191 & 0.787 \\
SAT1 & 0.156 & 0.085 & 0.204 & 0.200 & -0.082 & 0.762 \\
\hline
\end{tabular}

Secondly, exploratory factor analysis of intermediate variables was carried out. KMO and Bartlett's test of sphericity were performed on eight items of the intermediary variable (safety awareness, safety ability). As shown in Table 6, KMO is suitable for factor analysis. The probability of significance of the $\chi^{2}$ statistic is " 0.000 ", less than $1 \%$, indicating the data is relevant and meets the criteria.

Table 6. Intermediate variable's KMO and Bartlett test.

\begin{tabular}{ccc}
\hline \multicolumn{2}{c}{ KMO } & $\mathbf{0 . 8 7 5}$ \\
\hline \multirow{3}{*}{ Bartlett's test of sphericity } & Approximate chi-square & 600.524 \\
& df & 28 \\
& Significance probability & 0.000 \\
\hline
\end{tabular}

SPSS24.0 was used to carry out exploratory factor analysis on the medium variable scale. The method of factor extraction was principal component analysis, and the method of rotation was the maximum variance method. All factors with eigenvalues greater than 1 were extracted. The eigenvalues of the two factors were 4.407 and 1.251, respectively, and the cumulative variance interpretation rate was $70.729 \%$. By analyzing the measurement items of different factors, it is proved that it is reasonable to set safety awareness and safety ability as intermediary variables.

Table 7 is the composition matrix after the medium variable is rotated. From the data in the table, it can be seen that eight items of measurement are well distributed under two principal component factors without cross-loading. Moreover, the factor load of each item under single factor is greater than 0.5 , which indicates that the data of the item under other factors are all less than 0.5 , the results showed that the data of items in the scale had good validity. 
Table 7. Composition matrix after rotation of intermediate variable.

\begin{tabular}{ccc}
\hline \multirow{2}{*}{ Items } & \multicolumn{2}{c}{ Compositions } \\
\cline { 2 - 3 } & $\mathbf{1}$ & $\mathbf{2}$ \\
\hline SAW4 & 0.878 & 0.101 \\
SAW3 & 0.809 & 0.210 \\
SAW2 & 0.773 & 0.344 \\
SAW1 & 0.721 & 0.381 \\
SAB4 & 0.115 & 0.884 \\
SAB2 & 0.221 & 0.818 \\
SAB1 & 0.300 & 0.787 \\
SAB3 & 0.403 & 0.644 \\
\hline
\end{tabular}

Finally, the exploratory factor analysis of safety behavior was carried out. KMO and Bartlett's test of sphericity were performed on the seven items of safety behavior. As shown in Table 8, KMO is suitable for factor analysis. The probability of significance of the $\chi^{2}$ statistic is " 0.000 ", less than $1 \%$, indicating the data is relevant and meets the criteria.

Table 8. Safe behavior's KMO and Bartlett test.

\begin{tabular}{ccc}
\hline \multicolumn{2}{c}{ KMO } & $\mathbf{0 . 9 0 0}$ \\
\hline \multirow{3}{*}{ Bartlett's test of sphericity } & Approximate chi-square & 514.608 \\
& df & 21 \\
& Significance probability & 0.000 \\
\hline
\end{tabular}

SPSS24.0 was used for exploratory factor analysis of the safety behavior scale. The factor extraction method was principal component analysis, and the rotation method was the maximum variance method. All factors with characteristic value greater than 1 were extracted. Only one factor can be obtained by orthogonal rotation, the characteristic root is 4.266 , and the cumulative variance interpretation rate is $60.939 \%$. It is in accordance with the preset dimension, which proves the rationality of the scale setting.

Table 9 is the composition matrix after the rotation of the safe behavior. From the data in the table, it can be seen that the factor loads of each item of the seven measurement items are all over 0.5 under one principal component factor, which indicates that the item setting is more suitable, and all items may be retained.

Table 9. Composition matrix of safety behavior.

\begin{tabular}{cc}
\hline & Compositions \\
\cline { 2 - 2 } Items & $\mathbf{1}$ \\
\hline SB2 & 0.836 \\
SB3 & 0.820 \\
SB1 & 0.815 \\
SB5 & 0.769 \\
SB4 & 0.752 \\
SB7 & 0.738 \\
SB6 & 0.728 \\
\hline
\end{tabular}

\subsection{Confirmatory Factor Analysis}

The remaining 202 questionnaires without the deleted items were used to do confirmatory factor analysis (CFA) using Amos software 24.0 in this study. According to the conceptual model and EFA results, a structural equation model could be established to measure the effect of safety climate on worker's safety behavior in subway operation, as depicted in Figure 2. The observed variable is 
represented as a rectangle, the latent construct is represented as an oval, and the residual is represented as round. Moreover, the arrow between latent constructs represents the influence relationship.

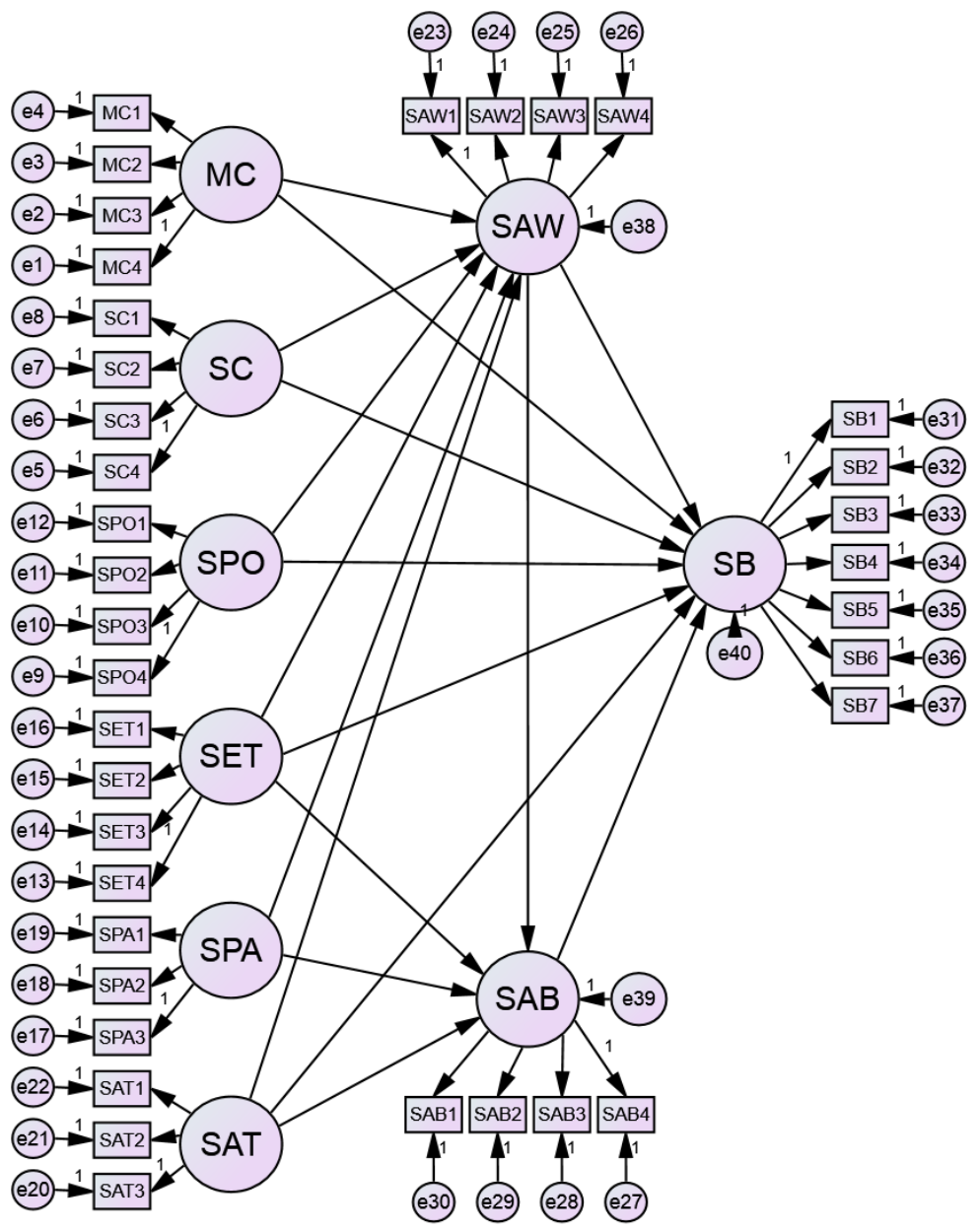

Figure 2. The structural equation model.

Further, chi-square, root mean square error of approximation (RMSEA), goodness-of-fit (GFI), Tucker Lewis index (TLI), and standardized root mean residual (SRMR) are employed to judge the goodness-of-fit of data. In addition, the average fitting index (IFI), comparative fitting index (CFI), and frugality adjustment index (PGFI, PCFI) can be used as auxiliary discrimination.

Convergent validity of the model can be estimated through factor loading, composite reliability (CR), and average variance extracted (AVE). As a good rule of thumb, standardized factor loadings should be greater than or equal to 0.50 due to statistical significance. The minimum thresholds of CR and AVE are 0.7 and 0.5 , respectively.

\subsubsection{Confirmatory Factor Analysis of Safe Climate}

(1) Construct validity of safety climate

Using the software Amos24.0, the safety climate was analyzed by confirmatory factor analysis (CFA) to analyze its construct validity. According to the relevant criteria in Table 10, the fitting degree of the safety climate model is good, and all meet the corresponding standards. 
Table 10. Fit index of safety climate structure validity.

\begin{tabular}{cccccccccc}
\hline Fit Index & $\chi^{2} / d f$ & RMR & RMSEA & GFI & TLI & IFI & CFI & PGFI & PCFI \\
\hline $\begin{array}{c}\text { Fitness threshold } \\
\text { model }\end{array}$ & $<3$ & $<0.08$ & $<0.08$ & $>0.8$ & $>0.9$ & $>0.9$ & $>0.9$ & $>0.5$ & $>0.5$ \\
& 2.121 & 0.043 & 0.075 & 0.840 & 0.900 & 0.918 & 0.916 & 0.644 & 0.770 \\
\hline
\end{tabular}

(2) Convergent validity of safety climate

As shown in Table 11, in the causal path, the absolute values of all path coefficients CR were greater than the reference value criterion of 0.7 , and $P<0.05$, indicating that a significant test had been passed.

Table 11. Fit Index of convergence validity of safety climate.

\begin{tabular}{cccccc}
\hline & Path & & Estimate & CR & AVE \\
\hline MC4 & $\leftarrow$ & MC & 0.786 & & \\
MC3 & $\leftarrow$ & MC & 0.793 & 0.886 & 0.660 \\
MC2 & $\leftarrow$ & MC & 0.823 & & \\
MC1 & $\leftarrow$ & MC & 0.845 & & \\
SC4 & $\leftarrow$ & SC & 0.756 & & \\
SC3 & $\leftarrow$ & SC & 0.822 & 0.842 & 0.574 \\
SC2 & $\leftarrow$ & SC & 0.814 & & \\
SC1 & $\leftarrow$ & SC & 0.621 & & \\
SPO4 & $\leftarrow$ & SPO & 0.732 & & \\
SPO3 & $\leftarrow$ & SPO & 0.724 & 0.845 & 0.577 \\
SPO2 & $\leftarrow$ & SPO & 0.802 & & \\
SPO1 & $\leftarrow$ & SPO & 0.777 & & \\
SET4 & $\leftarrow$ & SET & 0.681 & & \\
SET3 & $\leftarrow$ & SET & 0.857 & \multirow{2}{*}{0.862} & 0.611 \\
SET2 & $\leftarrow$ & SET & 0.830 & & \\
SET1 & $\leftarrow$ & SET & 0.747 & & \\
SPA3 & $\leftarrow$ & SPA & 0.910 & & \\
SPA2 & $\leftarrow$ & SPA & 0.814 & 0.892 & 0.734 \\
SPA1 & $\leftarrow$ & SPA & 0.843 & & \\
SAT3 & $\leftarrow$ & SAT & 0.818 & & \\
SAT2 & $\leftarrow$ & SAT & 0.635 & 0.753 & 0.507 \\
SAT1 & $\leftarrow$ & SAT & 0.670 & & \\
\hline & & & & & \\
\hline
\end{tabular}

(3) Discriminant validity of safety climate

According to Table 12 , there is a significant correlation among the dimensions $(P<0.01)$, and the correlation coefficient is less than the square root of AVE, which means there is a certain correlation among the latent variables, and there is a certain degree of differentiation between them. Therefore, the discriminant validity of this scale is ideal. The diagonal in the table is the AVE value.

Table 12. Fit index of safety climate discrimination validity.

\begin{tabular}{ccccccc}
\hline & MC & SC & SPO & SET & SPA & SAT \\
\hline MC & 0.660 & & & & & \\
SC & 0.595 & 0.574 & & & & \\
SPO & 0.676 & 0.694 & 0.577 & & & \\
SET & 0.557 & 0.535 & 0.754 & 0.611 & & \\
SPA & 0.487 & 0.713 & 0.616 & 0.614 & 0.734 & \\
SAT & 0.419 & 0.395 & 0.513 & 0.420 & 0.263 & 0.507 \\
Square root of AVE & 0.812 & 0.758 & 0.760 & 0.782 & 0.857 & 0.712 \\
\hline
\end{tabular}

4.4.2. Confirmatory Factor Analysis of Intermediate Variable

(1) Construct validity of Intermediate variable 
As shown in Table 13, the $\chi^{2} / d f$ value of the mediating variable is 2.090 , the values of rand RMSEA are all less than 0.08 , the indexes of GFI, TLI, IFI, and CFI are all more than 0.9 , and the values of PGFI and PCFI are also more than 0.5. The results show that the data fitting degree of the medium variable is good and meets the critical value requirement of each index.

Table 13. Fit index of intermediate variable structure validity.

\begin{tabular}{|c|c|c|c|c|c|c|c|c|c|}
\hline Fit Index & $\chi^{2} / d f$ & RMR & RMSEA & GFI & TLI & IFI & CFI & PGFI & PCFI \\
\hline Fitness threshold & $<3$ & $<0.08$ & $<0.08$ & $>0.8$ & $>0.9$ & $>0.9$ & $>0.9$ & $>0.5$ & $>0.5$ \\
\hline model & 2.090 & 0.018 & 0.074 & 0.953 & 0.951 & 0.967 & 0.967 & 0.503 & 0.656 \\
\hline
\end{tabular}

(2) Convergent validity of intermediate variable

As shown in Table 14, the absolute value of the path coefficient CR is above 0.8 , while the AVE value is above 0.6 , and all the indexes are above the critical value. The results show that the validity of the questionnaire data of safety awareness and safety ability is ideal, and the fitting degree of the model of safety awareness and safety ability is good.

Table 14. Fit index of convergence validity of intermediate variable.

\begin{tabular}{cccccc}
\hline & Path & & Estimate & CR & AVE \\
\hline SAW4 & $\leftarrow$ & SAW & 0.684 & & \\
SAW3 & $\leftarrow$ & SAW & 0.804 & \multirow{2}{*}{0.814} & 0.524 \\
SAW2 & $\leftarrow$ & SAW & 0.707 & & \\
SAW1 & $\leftarrow$ & SAW & 0.695 & & \\
SAB4 & $\leftarrow$ & SAB & 0.586 & & \\
SAB3 & $\leftarrow$ & SAB & 0.781 & 0.822 & 0.539 \\
SAB2 & $\leftarrow$ & SAB & 0.823 & & \\
SAB1 & $\leftarrow$ & SAB & 0.725 & & \\
\hline
\end{tabular}

(3) Discriminant validity of intermediate variable

According to Table 15, there is a significant correlation between safety awareness and safety ability $(P<0.01)$, and the correlation coefficient between them is less than the square root of AVE; that is to say, there is a certain correlation between two intermediate variables, and there is a certain degree of distinction between them. Therefore, the discriminant validity of this scale is ideal.

Table 15. Fit index of intermediate variable discrimination validity.

\begin{tabular}{ccc}
\hline & SAW & SAB \\
\hline SAW & 0.524 & \\
SAB & 0.664 & 0.539 \\
Square root of Ave & 0.724 & 0.734 \\
\hline
\end{tabular}

\subsubsection{Confirmatory Factor Analysis of Safety Behavior}

(1) Construct validity of safety behavior

As shown in Table 16, the $\chi^{2} / d f$ value of safety behavior is 1.565, the RMR value and RMSEA value are less than 0.08 , the GFI, TLI, IFI, and CFI are all more than 0.9 , and PCFI is also more than 0.5 . Although PGFI is less than 0.5 , its value of 0.485 is close to 0.5 . The results show that the data fitting degree of safety behavior is good and meets the critical value requirements of each index. 
Table 16. Fit index of safety behavior structure validity.

\begin{tabular}{|c|c|c|c|c|c|c|c|c|c|}
\hline Fit Index & $x^{2} / d f$ & RMR & RMSEA & GFI & TLI & IFI & CFI & PGFI & PCFI \\
\hline Fitness threshold & $<3$ & $<008$ & $<0.08$ & $>0.8$ & $>0.9$ & $>0.9$ & $>0.9$ & $>0.5$ & $>0.5$ \\
\hline model & 1.565 & 0.009 & 0.053 & 0.971 & 0.983 & 0.989 & 0.989 & 0.485 & 0.659 \\
\hline
\end{tabular}

(2) Convergent validity of safety behavior

As shown in Table 17, the absolute value of path coefficient CR between safety behaviors is 0.899 , and the AVE value is 0.561 . This indicates that the convergence validity of safety behavior questionnaire data is ideal, and the fitting degree of safety behavior model is good.

Table 17. Fit index of convergence validity of safety behavior.

\begin{tabular}{cccccc}
\hline & Path & & Estimate & CR & AVE \\
\hline SB7 & $\leftarrow$ & SB & 0.735 & & \\
SB6 & $\leftarrow$ & SB & 0.724 & & \\
SB5 & $\leftarrow$ & SB & 0.803 & & \\
SB4 & $\leftarrow$ & SB & 0.780 & 0.899 & 0.561 \\
SB3 & $\leftarrow$ & SB & 0.775 & & \\
SB2 & $\leftarrow$ & SB & 0.690 & & \\
SB1 & $\leftarrow$ & SB & 0.728 & & \\
\hline
\end{tabular}

\subsection{Model Modification}

According the evaluation results, the SEM meets the corresponding requirements. Then, the SEM can be optimized by path analysis, which can test the aforementioned hypotheses. The critical ratio is used to do path analysis in this study. Critical ratio is the ratio between the parameter value and the standard error of the parameter, and it should be greater than 1.96 if $P$ is less than 0.05 . Model modification can be executed by deleting the non-significant paths one at a time. The path with lowest value of critical ratio should be regarded as the first candidate for deletion [57]. Following this trimming procedure, the final model can be obtained, as shown in Figure 3.

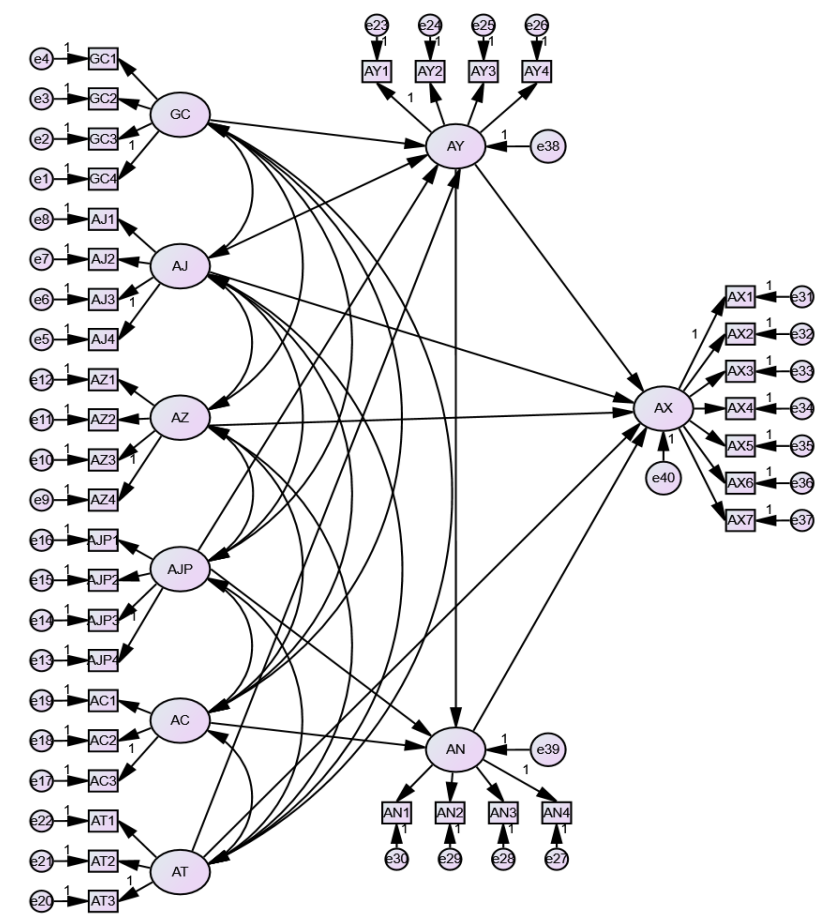

Figure 3. The final model. 
As shown in Table 18, this is the path analysis for the final model. The path coefficient of CR can be found by observation. The absolute value is between 2.049 and 3.843, which is much larger than the reference standard of 1.96. The standard error (SE) of each path coefficient was significantly reduced, and all passed the significance test. The "***" in the table means the $P$ value is too small to be shown.

Table 18. Path analysis.

\begin{tabular}{cccccccc}
\hline & Path & & Nonstandard Coefficient & Standard Coefficient & SE & CR & $p$ \\
\hline MC & $\rightarrow$ & SAW & 0.203 & 0.300 & 0.041 & 4.918 & $* * *$ \\
SC & $\rightarrow$ & SAW & 0.180 & 0.239 & 0.050 & 3.612 & $* * *$ \\
SET & $\rightarrow$ & SAW & 0.108 & 0.143 & 0.045 & 2.404 & 0.016 \\
SAT & $\rightarrow$ & SAW & 0.353 & 0.417 & 0.047 & 7.444 & $* * *$ \\
SET & $\rightarrow$ & SAB & 0.154 & 0.233 & 0.050 & 3.083 & 0.002 \\
SPA & $\rightarrow$ & SAB & 0.162 & 0.320 & 0.033 & 4.930 & $* * *$ \\
SAW & $\rightarrow$ & SAB & 0.298 & 0.341 & 0.062 & 4.776 & $* * *$ \\
SC & $\rightarrow$ & SB & 0.114 & 0.186 & 0.038 & 2.977 & 0.003 \\
SPO & $\rightarrow$ & SB & 0.153 & 0.238 & 0.039 & 3.957 & $* * *$ \\
SAT & $\rightarrow$ & SB & 0.154 & 0.223 & 0.040 & 3.831 & $* * *$ \\
SAB & $\rightarrow$ & SB & 0.213 & 0.228 & 0.048 & 4.428 & $* * *$ \\
SAW & $\rightarrow$ & SB & 0.205 & 0.251 & 0.065 & 3.130 & 0.002 \\
\hline
\end{tabular}

As shown in Table 19, the bootstrap mediator effect test is standardized. The intermediate effect of the model was tested by the bootstrap program in the structural equation model. Using the repeated random sampling method, 1000 bootstrap samples were sampled from the data $(\mathrm{N}=352)$, an approximate sampling distribution was generated, and the $90 \%$ confidence interval of the mediating effect was estimated by the 5th percentile and 95th percentile. It is obvious that the confidence interval of the data does not include 0 , which indicates that the mediating effect is statistically significant.

Table 19. Standardized bootstrap intermediate effect test.

\begin{tabular}{cllcccccccc}
\hline & \multirow{2}{*}{ Path } & & \multirow{2}{*}{ Estimate } & SE & \multicolumn{3}{c}{ Bias-Corrected 90\%CI } & \multicolumn{3}{c}{ Percentile 90\%CI } \\
\cline { 5 - 10 } & & & & Lower & Upper & $p$ & Lower & Upper & $p$ \\
\hline MC & $\rightarrow$ & SAW & 0.300 & 0.079 & 0.106 & 0.294 & 0.002 & 0.109 & 0.299 & 0.002 \\
SC & $\rightarrow$ & SAW & 0.239 & 0.080 & 0.077 & 0.275 & 0.004 & 0.079 & 0.276 & 0.004 \\
SET & $\rightarrow$ & SAW & 0.143 & 0.076 & 0.013 & 0.212 & 0.067 & 0.009 & 0.206 & 0.081 \\
SAT & $\rightarrow$ & SAW & 0.417 & 0.065 & 0.248 & 0.450 & 0.003 & 0.255 & 0.455 & 0.002 \\
SET & $\rightarrow$ & SAB & 0.233 & 0.090 & 0.065 & 0.264 & 0.003 & 0.052 & 0.254 & 0.005 \\
SPA & $\rightarrow$ & SAB & 0.320 & 0.067 & 0.100 & 0.226 & 0.002 & 0.099 & 0.226 & 0.002 \\
SAW & $\rightarrow$ & SAB & 0.341 & 0.074 & 0.172 & 0.415 & 0.003 & 0.179 & 0.422 & 0.002 \\
SC & $\rightarrow$ & SB & 0.186 & 0.087 & 0.034 & 0.220 & 0.030 & 0.034 & 0.221 & 0.030 \\
SPO & $\rightarrow$ & SB & 0.238 & 0.072 & 0.072 & 0.240 & 0.004 & 0.072 & 0.241 & 0.004 \\
SAT & $\rightarrow$ & SB & 0.223 & 0.074 & 0.067 & 0.251 & 0.007 & 0.071 & 0.253 & 0.005 \\
SAB & $\rightarrow$ & SB & 0.228 & 0.054 & 0.129 & 0.302 & 0.001 & 0.125 & 0.295 & 0.002 \\
SAW & $\rightarrow$ & SB & 0.251 & 0.117 & 0.042 & 0.358 & 0.048 & 0.038 & 0.355 & 0.051 \\
\hline
\end{tabular}

\subsection{Running Results of Final Model}

The standardized path coefficient among latent constructs in final model can be obtained by calculation, as shown in Figure 4. 


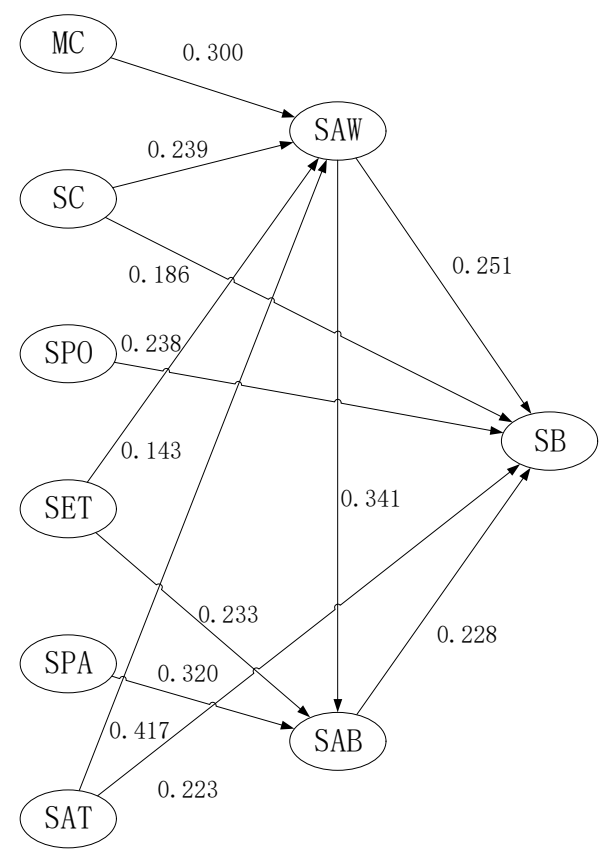

Figure 4. The standardized path coefficient in final model.

\section{Discussion}

\subsection{Discussion of Findings}

The influence effects among latent constructs can be divided into three kinds, including direct influence effect, indirect influence effect, and total influence effect. The direct influence effect is the direct effect of the causal variable on the resulting variable; it is measured by the path coefficient. The indirect effect is the indirect effect of the causal variable on the resulting variable by influencing the mediator variables. The total influence effect is the sum of the direct influence effect and indirect influence effect, and it can comprehensively reflect the influence effect of each latent construct on safety behavior. The direct, indirect, and total influence effect among latent constructs are expatiated in Table 20. The descending order of total influence effect of safety climate on safety behavior is SAT, SC, SPO, SET, MC, and SPA, and the values of total influence effect are 0.360, 0.265, 0.238, 0.100, 0.099, and 0.073 , respectively. In addition, the total influence effects of SAW and SAB are 0.329 and 0.228 , respectively. The SET, MC, and SPA have the lowest impact on safety behavior. It can be explained that SPA, MC, and SET only bring indirect impact to safety behavior by promoting safety awareness and improving safety ability. However, the indirect influence is far less than direct influence according to the computation rule. This is why SET, MC, and SPA have a low impact on safety behavior.

Table 20. The influence effect among latent constructs.

\begin{tabular}{cccccccccc}
\hline \multirow{2}{*}{ Latent Constructs } & \multicolumn{3}{c}{ SAW } & \multicolumn{3}{c}{ SAB } & \multicolumn{3}{c}{ SB } \\
\cline { 2 - 9 } & Direct & Indirect & Total & Direct & Indirect & Total & Direct & Indirect & Total \\
\hline MC & 0.300 & & 0.300 & & 0.102 & 0.102 & & 0.099 & 0.099 \\
SC & 0.239 & & 0.239 & & 0.081 & 0.081 & 0.186 & 0.079 & 0.265 \\
SPO & & & & & & & 0.238 & & 0.238 \\
SET & 0.143 & & 0.143 & 0.233 & 0.049 & 0.282 & & 0.100 & 0.100 \\
SPA & & & 0.320 & & 0.320 & & 0.073 & 0.073 \\
SAT & 0.417 & & 0.417 & & 0.142 & 0.142 & 0.223 & 0.137 & 0.360 \\
SAW & & & 0.341 & & 0.341 & 0.251 & 0.078 & 0.329 \\
SAB & & & & & & 0.228 & & 0.228 \\
\hline
\end{tabular}




\subsection{Potential Contributions for Subway Operation Safety Management}

The potential contributions of this study can be summarized as follows. First, the proposed dimensions and indicators could be used to measure the safety climate of subway operation. The scale could be altered for various subways in different cities and more details are needed to tailor its application. Second, it is beneficial to understand the mechanisms of safety climate influences on worker' safety behavior. The influence paths are identified and their standardized path coefficients are calculated and analyzed. It is evident that the formation of safety behavior in subway operation can be traced back to management and individual level. The study could enable staff in their daily work to be more conscious to avoid unsafe behavior, enhance their own safety awareness, and improve their own safety ability. Meanwhile, employees can also find problems at work and put forward methods and countermeasures to improve safety management. Third, it is beneficial to enhance the safety performance by paying more attention to the key influence paths and indicators. For instance, managers and supervisors should put more focus on safety communication, safety policy, and safety attitude. It is beneficial to reduce the occurrence of operational accidents due to the unsafe behavior of employees. In order to promote safety management and sustainable development, it is possible to apply this type of study in other regions of the world, such as Europe and the United States. According to the actual situation in different regions, the research results and suggestions could be obtained through this research process.

\subsection{Limitations of This Research}

There is no mature measurement scale for exploring the effects of safety climate on worker's safety behavior in subway operation, and the safety behavior scale of other research area sis used for reference in this study. Two limitations need to be taken into account to interpret the research results. First, six dimensions (MC, SC, SPO, SET, SPA, and SAT) are used to measure safety climate, and two mediator variables (SAW and SAB) are taken into account in subway operation. Some unimportant and negligible factors may not be considered in this study. Second, this study is only implemented at project level (Xuzhou subway) and suitable sample size. The results may be slightly different in Shanghai or Beijing. Future study is needed to seek a larger sample size and consolidate the results of this study.

\subsection{Suggestions}

According to the research results and discussion, it can be seen that relevant effective measures should be taken to promote the safety behavior of subway operation workers. First, enhancing safety communication in daily work: Sharing safety knowledge, experience, and opinions will help to improve the safety behavior to a large extent. Hence, creating a good organizational environment is also important. Subway enterprises should encourage safe communication among employees, cultivate the concept of safe communication, and maintain a good safe communication channel to ensure timely feedback and resolution of problems. Second, developing and implementing perfect safety policies: Safety policy should be updated according to operating experience and occurred accidents continuously. Third, strengthening safety training: Subway operation companies should pay attention to safety education and training of workers. It will help workers to acquire sufficient safety knowledge and safety skills, and then the workers could avoid a variety of low-level error and reduce unsafety behavior. Fourth, implementing management safety commitment: Due to the particularity of management status, its attitude and behavior towards safety have a great impact on the workers. If the workers can deeply appreciate the management's safety commitment, they will be incentivized to enhance safety awareness and improve safety behavior. Fifth, encouraging safety participation: Workers can improve their safety performance by participating in safety activities, such as developing safety plans and accident prevention measures. 


\section{Conclusions}

This research aimed to improve the understanding and insight into the mechanism by which safety climate and individual factors affect worker's safety behavior in subway operation. It was envisaged that this study could help managerial personnel to deeply understand the shaping mechanisms of safety behavior and the develop necessary corresponding strategies that can improve safety management in the complex and dynamic subway operating environment.

In this study, a conceptual model of the effect of safety climate on safety behavior was constructed at first, and the data were subsequently collected by a questionnaire survey in Xuzhou subway operation company. Then, SPSS software 24.0 and Amos software 24.0 were employed to analyze the data and structural equation model. The main results are as follows. The hypothesis that management commitment has a positive and direct influence on safety awareness is supported, but its impact on safety behavior is invalid. Management commitment can have an indirect impact on safety behavior through safety awareness and safety ability, and its total influence effect is 0.099 . The hypothesis that safety communication has a positive and direct influence on safety awareness and safety behavior is supported. Safety communication can have an indirect impact on safety behavior through safety awareness and safety ability, and its total influence effect is 0.265 . The hypothesis that safety policy has a positive and direct influence on safety behavior is supported, but its impact on safety awareness is invalid. Its total influence effect is 0.238 . The hypothesis that safety education has a positive and direct influence on safety awareness and safety ability is supported, but its impact on safety behavior is invalid. Safety education can have an indirect impact on safety behavior through safety awareness and safety ability, and its total influence effect is 0.100 . The hypothesis that safety participation has a positive and direct influence on safety ability is supported, but its impact on safety awareness is invalid. Safety participation can have an indirect impact on safety behavior through safety ability, and its total influence effect is 0.073 . The hypothesis that safety attitude has a positive and direct influence on safety awareness and safety behavior is supported, but its impact on safety ability is invalid. Safety attitude can have an indirect impact on safety behavior through safety awareness and safety ability, and its total influence effect is 0.360 . The hypothesis that safety awareness has a positive and direct influence on safety ability and safety behavior is supported. Safety awareness can have an indirect impact on safety behavior through safety ability, and its total influence effect is 0.329 . The hypothesis that safety ability has a positive and direct influence on safety behavior is supported. Its total influence effect is 0.228 . The total effect of safety climate on safety behavior was as follows: safety attitude (0.360), safety communication (0.265), safety policy (0.238), safety education and training (0.100), management commitment (0.099), and safety participation (0.073). The total effects of safety awareness and safety capability on safety behavior were 0.329 and 0.228 , respectively. It is not difficult to see that for safety education training, management commitment, and safety participation, the effect of exerting influence on safety behavior through only intermediate variables is relatively small, which is why they are ranked last. However, it also gives us a deeper understanding of the dimensions, as well as targeted improvement measures to provide a certain basis.

The research results provide strong support for promoting understanding of the formation mechanism of safe behavior in subway operation. This study demonstrates the reliability and validity of the proposed structural equation model. The final model indicates that safety behavior is directly or indirectly influenced by management commitment, safety communication, safety policy, safety education and training, safety participation, and safety attitude. It also demonstrates that the safety climate influences safety behavior directly and indirectly through its effects on safety awareness and safety ability. The findings offer valuable guidance for subway operation safety managers to identify the mechanisms by which they could promote safety management level.

This study also can provide practical insights into subway operation safety and a theoretical foundation for safety strategies and safety management. For instance, senior managers have to be convinced of the important and significant influences of management commitment to safety behavior 
in subway operation. Hence, it is important to give a higher priority to subway operation safety and implement essential safety practices in all circumstances.

Author Contributions: Formal analysis: H.G.; investigation: M.M.; project administration: Y.D.; writing—original draft: Y.Z.; writing-review \& editing: S.P. All authors have read and agreed to the published version of the manuscript.

Funding: The research described in this paper is supported by National Natural Science Foundation of China (71801214) and the Fundamental Research Funds for the Central Universities (2017QNB13). The authors also gratefully acknowledge those who provided data and suggestions.

Acknowledgments: The authors sincerely acknowledge the editors and anonymous reviewers for their valuable comments and constructive suggestions, which considerably improve the exposition of this work.

Conflicts of Interest: The authors declare no conflict of interest.

\section{References}

1. Agnew, C.; Flin, R.; Mearns, K. Patient safety climate and worker safety behaviors in acute hospitals in Scotland. J. Saf. Res. 2013, 45, 95-101. [CrossRef]

2. Beus, J.M.; Payne, S.C.; Bergman, M.E.; Arthur, W., Jr. Safety climate and injuries: An examination of theoretical and empirical relationships. J. Appl. Psychol. 2010, 95, 713-727. [CrossRef] [PubMed]

3. Zhou, Q.; Fang, D.; Wang, X. A method to identify strategies for the improvement of human safety behavior by considering safety climate and personal experience. Saf. Sci. 2008, 46, 1406-1419. [CrossRef]

4. Fugas, C.S.; Silva, S.A.; Melia, J.L. Another look at safety climate and safety behavior: Deepening the cognitive and social mediator mechanisms. Accid. Anal. Prev. 2012, 45, 468-477. [CrossRef] [PubMed]

5. Cartenì, A.; Henke, I.; Molitierno, C.; Di Francesco, L. Strong sustainability in public transport policies: An e-mobility bus fleet application in Sorrento Peninsula (Italy). Sustainability 2020, 12, 7033. [CrossRef]

6. Ko, Y.D.; Oh, Y. Efficient Deployment Design of Wireless Charging Electric Tram System with Battery Management Policy. Sustainability 2020, 12, 2920. [CrossRef]

7. Macioszek, E.; Świerk, P.; Kurek, A. The bike-sharing system as an element of enhancing sustainable mobility-A case study based on a city in Poland. Sustainability 2020, 12, 3285. [CrossRef]

8. Macioszek, E.; Kurek, A. The use of a park and ride system-A case study based on the city of Cracow (Poland). Energies 2020, 13, 3473. [CrossRef]

9. Corazza, M.V.; Imbastaro, S.; Pascucci, M. Regenerating communities. New local railway: A technological and environmental study. Sustainability 2020, 12, 3693. [CrossRef]

10. Deng, Y.; Li, Q.; Lu, Y. A research on subway physical vulnerability based on network theory and FMECA. Saf. Sci. 2015, 80, 127-134. [CrossRef]

11. Heinrich, H.W. Industrial Accident Prevention: A Scientific Approach, 2nd ed.; McGraw-Hill Book Company, Inc.: New York, NY, USA, 1941; p. 448.

12. Neal, A.; Griffin, M.A.; Hart, P.M. The impact of organizational climate on safety climate and individual behavior. Saf. Sci. 2000, 34, 99-109. [CrossRef]

13. Shen, L.; Jiao, L.; He, B.; Li, L. Evaluation on the utility efficiency of metro infrastructure projects in China from sustainable development perspective. Int. J. Proj. Manag. 2015, 33, 528-536. [CrossRef]

14. Wan, X.; Li, Q.; Yuan, J.; Schonfeld, P.M. Metro passenger behaviors and their relations to metro incident involvement. Accid. Anal. Prev. 2015, 82, 90-100. [CrossRef] [PubMed]

15. Dinkel, A.; Baumert, J.; Erazo, N.; Ladwig, K. Jumping, lying, wandering: Analysis of suicidal behaviour patterns in 1,004 suicidal acts on the German railway net. J. Psychiatr. Res. 2011, 45, 121-125. [CrossRef] [PubMed]

16. Niederkrotenthaler, T.; Sonneck, G.; Dervic, K.; Nader, I.W.; Voracek, M.; Kapusta, N.D.; Etzersdorfer, E.; Mittendorfer-Rutz, E.; Dorner, T. Predictors of suicide and suicide attempt in subway stations: A populationbased ecological study. J. Urban. Health 2012, 89, 339-353. [CrossRef] [PubMed]

17. Zhang, X.; Deng, Y.; Li, Q.; Skitmore, M.; Zhou, Z. An incident database for improving metro safety: The case of shanghai. Saf. Sci. 2016, 84, 88-96. [CrossRef]

18. Kyriakidis, M.; Hirsch, R.; Majumdar, A. Metro railway safety: An analysis of accident precursors. Saf. Sci. 2012, 50, 1535-1548. [CrossRef] 
19. Chen, Y.; McCabe, B.; Hyatt, D. Impact of individual resilience and safety climate on safety performance and psychological stress of construction workers: A case study of the Ontario construction industry. J. Saf. Res. 2017, 61, 167-176. [CrossRef]

20. Zohar, D. Safety climate in industrial organizations: Theoretical and applied implications. J. Appl. Psychol. 1980, 65, 96-102. [CrossRef]

21. Zohar, D. Thirty years of safety climate research: Reflections and future directions. Accid. Anal. Prev. 2010, 42, 1517-1522. [CrossRef]

22. Morello, R.T.; Lowthian, J.A.; Barker, A.L.; McGinnes, R.; Dunt, D.; Brand, C. Strategies for improving patient safety culture in hospitals: A systematic review. BMJ Qual. Saf. 2013, 22, 11-18. [CrossRef] [PubMed]

23. Petitta, L.; Probst, T.M.; Barbaranelli, C.; Ghezzi, V. Disentangling the roles of safety climate and safety culture: Multi-level effects on the relationship between supervisor enforcement and safety compliance. Accid. Anal. Prev. 2017, 99, 77-89. [CrossRef] [PubMed]

24. O'Connor, P.; O’Dea, A.; Kennedy, Q.; Buttrey, S.E. Measuring safety climate in aviation: A review and recommendations for the future. Saf. Sci. 2011, 49, 128-138. [CrossRef]

25. Wu, C.; Song, X.; Wang, T.; Fang, D. Core dimensions of the construction safety climate for a standardized safety-climate measurement. J. Constr. Eng. Manag. 2015, 141. [CrossRef]

26. Bosak, J.; Coetsee, W.J.; Cullinane, S. Safety climate dimensions as predictors for risk behavior. Accid. Anal. Prev. 2013, 55, 256-264. [CrossRef]

27. Dov, Z. Safety climate and beyond: A multi-level multi-climate framework. Saf. Sci. 2008, 46, $376-387$. [CrossRef]

28. Fogarty, G.J.; Shaw, A. Safety climate and the Theory of Planned Behavior: Towards the prediction of unsafe behavior. Accid. Anal. Prev. 2010, 42, 1455-1459. [CrossRef]

29. Lingard, H.; Cooke, T.; Blismas, N. Do perceptions of supervisors' safety responses mediate the relationship between perceptions of the organizational safety climate and incident rates in the construction supply chain? J. Constr. Eng. Manag. 2012, 138, 234-241. [CrossRef]

30. Smith, T.D.; Eldridge, F.; DeJoy, D.M. Safety-specific transformational and passive leadership influences On firefighter safety climate perceptions and safety behavior outcomes. Saf. Sci. 2016, 86, 92-97. [CrossRef]

31. Zohar, D.; Polachek, T. Discourse-based intervention for modifying supervisory communication as leverage for safety climate and performance improvement: A randomized field study. J. Appl. Psychol. 2014, 99, 113-124. [CrossRef]

32. Kapp, E.A. The influence of supervisor leadership practices and perceived group safety climate on employee safety performance. Saf. Sci. 2012, 50, 1119-1124. [CrossRef]

33. Mohamed, S.; Ali, T.H.; Tam, W.Y.V. National culture and safe work behaviour of construction workers in Pakistan. Saf. Sci. 2009, 47, 29-35. [CrossRef]

34. Li, Q.; Ji, C.; Yuan, J.; Han, R. Developing dimensions and key indicators for the safety climate within China's construction teams: A questionnaire survey on construction sites in Nanjing. Saf. Sci. 2017, 93, 266-276. [CrossRef]

35. Beus, J.M.; Payne, S.C.; Arthur, W., Jr.; Munoz, G.J. The development and validation of a cross-industry safety climate measure: Resolving conceptual and operational issues. J. Manag. 2019, 45, 1987-2013.

36. Guo, B.H.W.; Yiu, T.W.; Gonzalez, V.A. Predicting safety behavior in the construction industry: Development and test of an integrative model. Saf. Sci. 2016, 84, 1-11. [CrossRef]

37. Nahrgang, J.D.; Morgeson, F.P.; Hofmann, D.A. Safety at Work: A Meta-Analytic Investigation of the Link Between Job Demands, Job Resources, Burnout, Engagement, and Safety Outcomes. J. Appl. Psychol. 2011, 96, 71-94. [CrossRef]

38. DeJoy, D.M.; Schaffer, B.S.; Wilson, M.G.; Vandenberg, R.J.; Butts, M.M. Creating safer workplaces: Assessing the determinants and role of safety climate. J. Saf. Res. 2004, 35, 81-90. [CrossRef]

39. Huang, Y.; Ho, M.; Smith, G.S.; Chen, P.Y. Safety climate and self-reported injury: Assessing the mediating role of employee safety control. Accid. Anal. Prev. 2006, 38, 425-433. [CrossRef]

40. Hsu, S.H.; Lee, C.; Wu, M.; Takano, K. The influence of organizational factors on safety in Taiwanese high-risk industries. J. Loss Prev. Process. Ind. 2010, 23, 646-653. [CrossRef]

41. Yulita; Dollard, M.F.; Idris, M.A. Climate congruence: How espoused psychosocial safety climate and enacted managerial support affect emotional exhaustion and work engagement. Saf. Sci. 2017, 96, 132-142. [CrossRef] 
42. Han, S.; Saba, F.; Lee, S.; Mohamed, Y.; Pena-Mora, F. Toward an understanding of the impact of production pressure on safety performance in construction operations. Accid. Anal. Prev. 2014, 68, 106-116. [CrossRef] [PubMed]

43. Campbell, J.; McCloy, R.; Oppler, S.; Sager, C. A Theory of Performance. In Personnel Selection in Organizations; Schmitt, N., Borman, W.C., Eds.; Jossey-Bass Publishers: San Francisco, CA, USA, 1993; pp. 35-70.

44. Christian, M.S.; Bradley, J.C.; Wallace, J.C.; Burke, M.J. Workplace safety: A meta-analysis of the roles of person and situation factors. J. Appl. Psychol. 2009, 94, 1103-1127. [CrossRef] [PubMed]

45. Griffin, M.A.; Curcuruto, M. Safety Climate in Organizations. Organ. Psychol. Organ. Behav. 2016, 3, 41015-62414.

46. Hofmann, D.A.P.U.; Stetzer, A. A cross-level investigation of factors influencing unsafe behaviors and accidents. Pers. Psychol. 1996, 49, 307-339. [CrossRef]

47. Griffin, M.A.; Neal, A. Perceptions of safety at work: A framework for linking safety climate to safety performance, knowledge, and motivation. J. Occup. Health Psychol. 2000, 5, 347-358. [CrossRef] [PubMed]

48. Probst, T.M.; Estrada, A.X. Accident under-reporting among employees: Testing the moderating influence of psychological safety climate and supervisor enforcement of safety practices. Accid. Anal. Prev. 2010, 42, 1438-1444. [CrossRef]

49. Liu, S.; Zhou, Y.; Cheng, Y.; Zhu, Y. Multiple mediating effects in the relationship between employees' trust in organizational safety and safety participation behavior. Saf. Sci. 2020, 125, 104611. [CrossRef]

50. Neal, A.; Griffin, M.A. A study of the lagged relationships among safety climate, safety motivation, safety behavior, and accidents at the individual and group levels. J. Appl. Psychol. 2006, 91, 946-953. [CrossRef]

51. Didla, S.; Mearns, K.; Flin, R. Safety citizenship behaviour: A proactive approach to risk management. J. Risk Res. 2009, 12, 475-483. [CrossRef]

52. Baysari, M.T.; McIntosh, A.S.; Wilson, J.R. Understanding the human factors contribution to railway accidents and incidents in Australia. Accid. Anal. Prev. 2008, 40, 1750-1757. [CrossRef]

53. Langford, B.C.; Chen, J.; Cherry, C.R. Risky riding: Naturalistic methods comparing safety behavior from conventional bicycle riders and electric bike riders. Accid. Anal. Prev. 2015, 82, 220-226. [CrossRef] [PubMed]

54. Aryee, S.; Hsiung, H. Regulatory focus and safety outcomes: An examination of the mediating influence of safety behavior. Saf. Sci. 2016, 86, 27-35. [CrossRef]

55. Choi, B.; Ahn, S.; Lee, S. Role of social norms and social identifications in safety behavior of construction workers. I: Theoretical model of safety behavior under social influence. J. Constr. Eng. Manag. 2017, 143, 04016124. [CrossRef]

56. Al-Refaie, A. Factors affect companies' safety performance in Jordan using structural equation modeling. Saf. Sci. 2013, 57, 169-178. [CrossRef]

57. Vinodkumar, M.N.; Bhasi, M. Safety management practices and safety behaviour: Assessing the mediating role of safety knowledge and motivation. Accid. Anal. Prev. 2010, 42, 2082-2093. [CrossRef]

58. Vredenburgh, A.G. Organizational safety: Which management practices are most effective in reducing employee injury rates? J. Saf. Res. 2002, 33, 259-276. [CrossRef]

59. Boker, S.; Neale, M.; Maes, H.; Wilde, M.; Spiegel, M.; Brick, T.; Spies, J.; Estabrook, R.; Kenny, S.; Bates, T.; et al. OpenMx: An open source extended structural equation modeling framework. Psychometrika 2011, 76, 306-317. [CrossRef]

60. Hellier, P.K.; Geursen, G.M.; Carr, R.A.; Rickard, J.A. Customer repurchase intention: A general structural equation model. Eur. J. Mark. 2003, 37, 1762-1800. [CrossRef]

61. Henseler, J.; Ringle, C.M.; Sarstedt, M. A new criterion for assessing discriminant validity in variance-based structural equation modeling. J. Acad. Mark. Sci. 2015, 43, 115-135. [CrossRef]

62. Ko, H.S.O.C.; Cho, C.C.O.J.; Roberts, M.S.C.O. Internet uses and gratifications: A structural equation model of interactive advertising. J. Advert. 2005, 34, 57-70. [CrossRef]

63. Cronbach, L.J. Coefficient alpha and the internal structure of tests. Psychometrika 1951, 16, 297-334. [CrossRef]

(C) 2020 by the authors. Licensee MDPI, Basel, Switzerland. This article is an open access article distributed under the terms and conditions of the Creative Commons Attribution (CC BY) license (http://creativecommons.org/licenses/by/4.0/). 